\title{
High Density Thickening and Gravity Transportation of Cuajone Tailings
}

\author{
J.H. Figueroa Southern Copper Corporation, Peru
}

J. Roman Southern Copper Corporation, Peru

\begin{abstract}
The mineral processing industry is facing more than ever restrictions in water availability; the lack of water resources is making to consider alternative processes, which lead to efficient water consumption operations. Such is the case of Southern Copper Corporation which is considering thickening technologies to recover water from the Cuajone tailings to assure the water requirements for its expansion projects. A pilot campaign was completed to investigate the feasibility of recovering water from the tailings. The tests were completed with the collaboration of three world leading companies in thickening technologies, and the results show that it is feasible to recover water from the Cuajone tailings to a rate of 315 litres/s and that the de-watered slurry can flow by gravity through the existing open channel systems.
\end{abstract}

\section{Introduction}

Tailings thickening has been studied at Southern Copper Corporation (SCC) in the past. The objectives of those studies were to get a paste consistency underflow; the reports showed that the project was technically possible but economically unaffordable because of the associated operating and capital costs, as the highly dewatered tailings (paste) had to be transported to the final disposal site about $30 \mathrm{~km}$ away, requiring positive displacements pumps and piping systems.

In spite of the negative results from the previous studies, SCC has taken a new approach to thickening technology, and a pilot program was scheduled to evaluate thickening of the tailing to a high density consistency through high compression technologies. Close control of the under flow rheological properties was required to assure the tailing would flow by gravity in the existing open channels.

\section{General considerations}

SCC has two major operations in Perú, which are the Cuajone and Toquepala Mines. Both of them share a final tailing disposal dam called Quebrada Honda, located near Toquepala. The Cuajone tailings are transported to Toquepala Mine through a $1-1.5 \%$ sloped channel system. Both tailings are then mixed and transported by gravity to the final deposition site, as shown below.

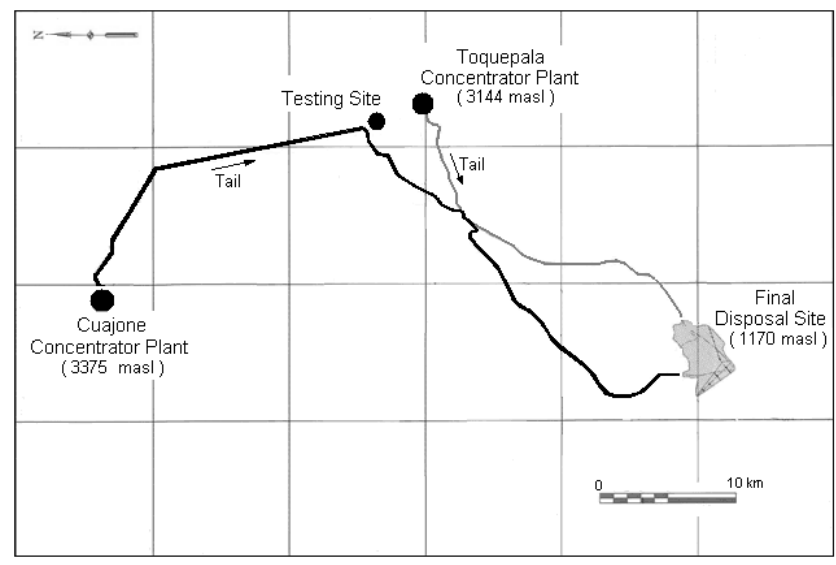

Figure 1 Schematic diagram of the tailings disposal system 
Because of the slurry rheology and the channel system characteristics, the Cuajone tailings are discharged at an average solids density of $52 \%$ by mass $(87,000 \mathrm{tpd})$. As the Cuajone tailings are known for their difficult mineralogical properties, SCC considered it necessary for the participation of the three major thickening technology providers to run the pilot test simultaneously. The three pilot plants were installed near Toquepala Operations. The expected recovered water at industrial scale is planned to be used at the Toquepala expansion project.

The pilot test was programmed to run continuously for six weeks, and special care has been taken to provide a representative sample to each pilot plant. The sample was taken from the drop box at the channel discharge (testing site), and the sample collection and distribution system was especially designed for this purpose.

\section{$3 \quad$ Pilot plant testing}

\subsection{Objectives}

The objectives of the pilot test were to reach a high density underflow due to the effect of residence time and high compression given by the height of the bed; the highly dewatered slurry must flow under gravity through the existing channels to the final disposal dam; and the recovery of water at a rate and specifications suitable to be used in the Toquepala Flotation circuit must be achieved.

\subsection{Tailings characterisation}

Special attention was given to the feed sampling and characterisation, because of the special behaviour and rheological properties of the Cuajone tailings. It required close coordination with the Mine and Concentrator Plant in order to process during the test period the major ore occurrence in the Mine. During the tests mostly minerals containing predominantly Porfiritic latite and Intrusive andesite rocks were delivered to the Cuajone concentrator plant.

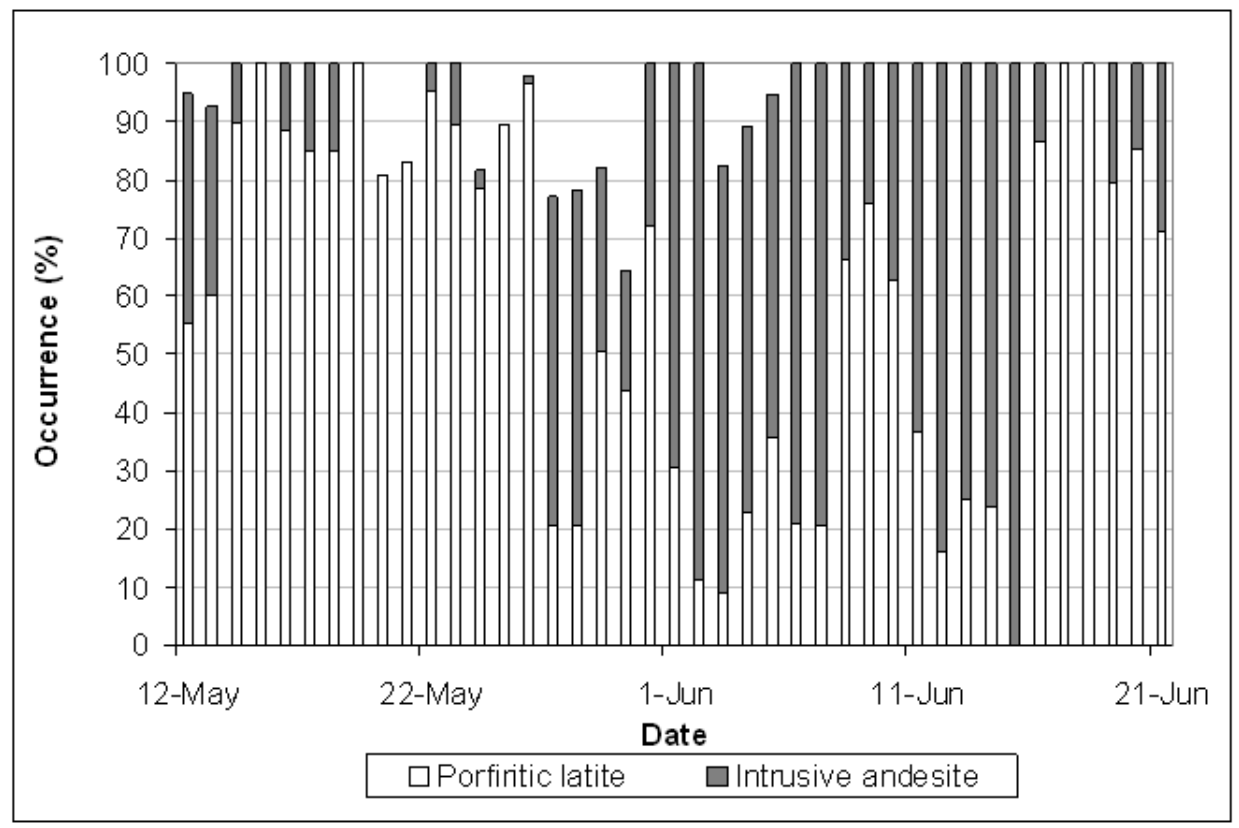

Figure 2 Mineral delivered to Cuajone concentrator plant - testing period

It is important to consider that there is a delay of 24 to 48 hours for the mineral delivered to the Concentrator Plant to arrive to the testing site; it will depend on the daily stock pile height plus the process residence time and transportation time of the tailings through about $25 \mathrm{~km}$ of channel system. 
The daily composite characterisation shows that the mineral containing predominantly intrusive andesite rocks are finer compared with those samples predominantly composed by porfiritic latite rocks, as shown in Figure 3. The andesite main characteristic is the high clay content, which makes this material resistant to thickening, as shown in the results of the test program.

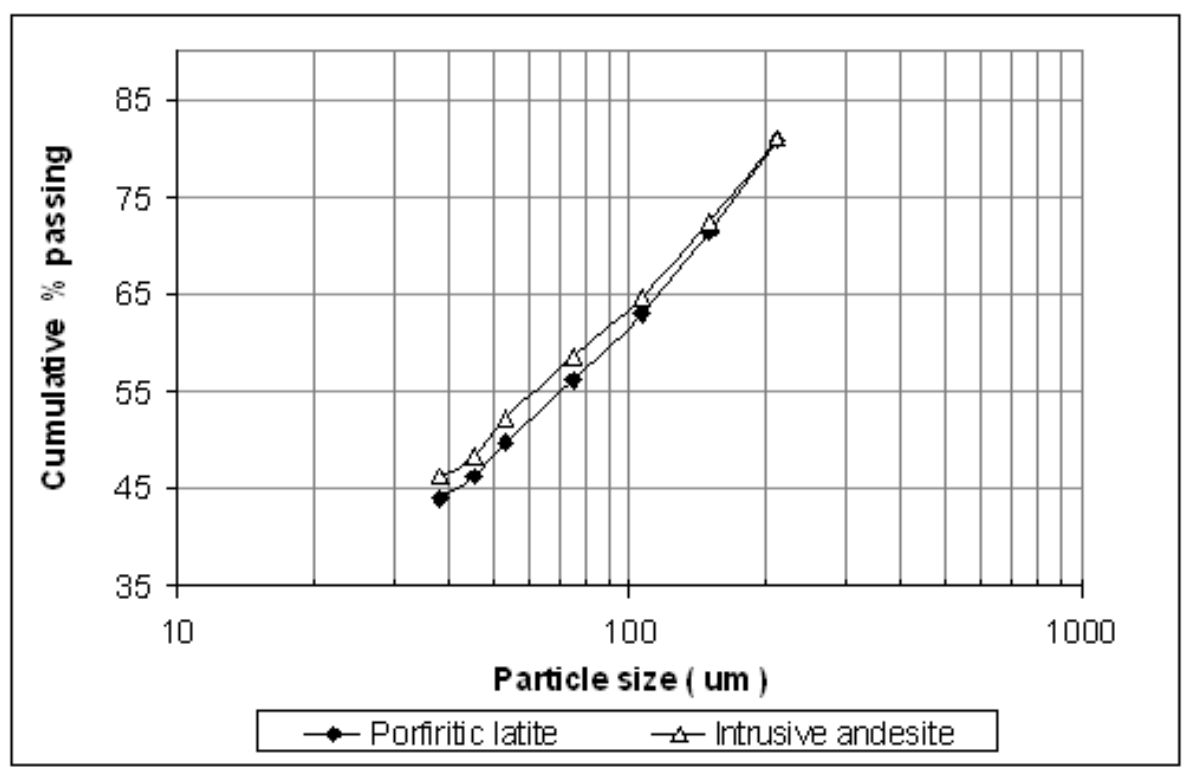

\section{Figure 3 Average granulometry - daily feed composite}

Rheological tests were done over samples representing both materials, thus synthetic thickened samples were prepared in order to measure the rheological properties at different $\%$ solids. The results show that the intrusive andesite rocks present highly more resistance to flow, as the yield stress is significantly higher than the mineral with predominance of porfiritic latite rocks.

Figure 4 shows the different rheological response of both kind of materials, which means that those mineral containing primarily andesitic rocks will limit the flow capacity of the tailing, as a matter of fact those differences increase at higher solids density.

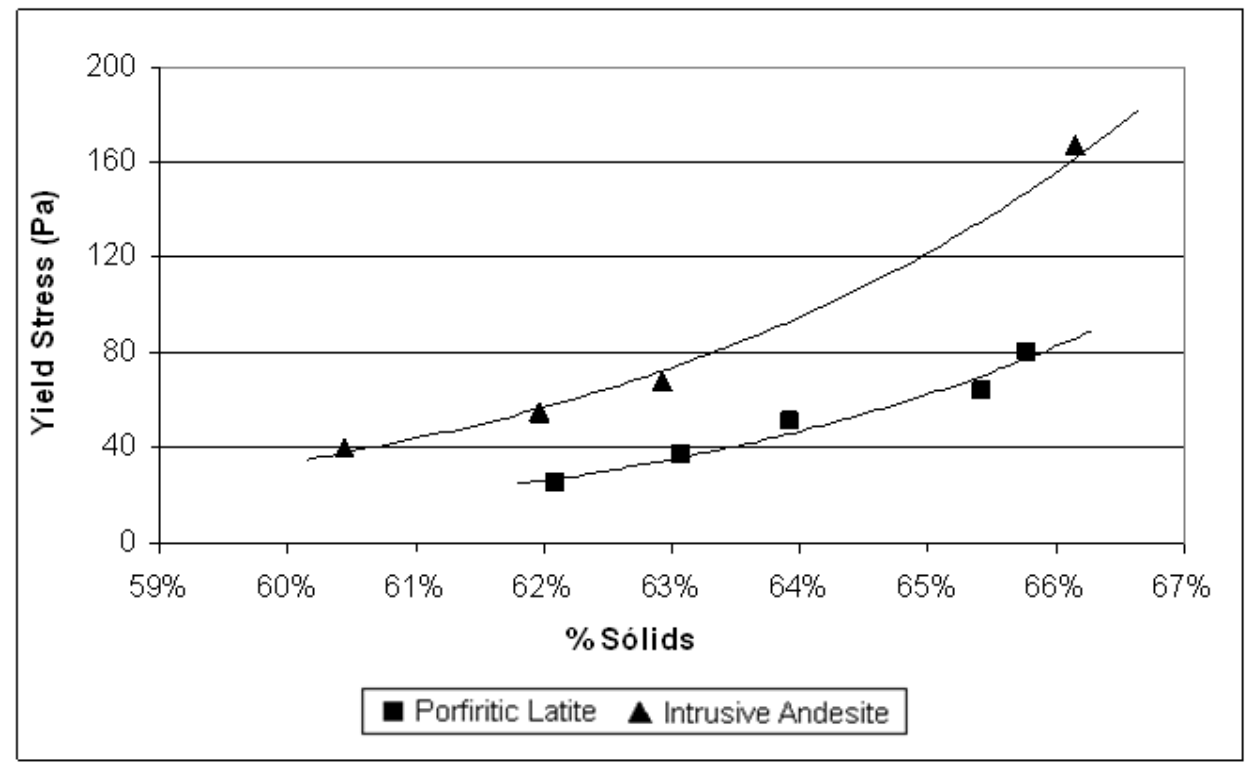

Figure 4 Yield stress of mineral with predominance of andesite and latite rocks 


\subsection{Testing program}

A detailed program was developed to evaluate the performance of each technology used for the thickening of the Cuajone tailings. Special attention was taken to supply each technology provider the same quality of the feed tailings; also the flocculent type was the same in order to compare the performance of each one.

Table 1 Pilot plant testing program

\begin{tabular}{llll}
\hline Phase & Period & $\begin{array}{l}\text { Objective \% Solids } \\
\text { Underflow }\end{array}$ & Flocculent \\
\hline I & May 12 - May 16 & $63 \%$ & Floerger 923 \\
II & May 16- May 22 & $65 \%$ & Floerger 923 \\
II & May 22 - May 27 & $67 \%$ & Floerger 923 \\
IV & May 27- May 30 & $69 \%$ & Floerger 923 \\
V & May 30 - Jun 18 & $65-66 \%$ & Floerger 923 \\
VI & Jun 18 - Jun 21 & $65-66 \%$ & Praestrol 2530 \\
\hline
\end{tabular}

\subsection{Pilot tests results}

The average results of the three pilot plants running simultaneously are shown below in Figure 5. Even though the performance of one operator (technology provider) significantly differs from the other two, the three of them get the same response from the Cuajone tailings.

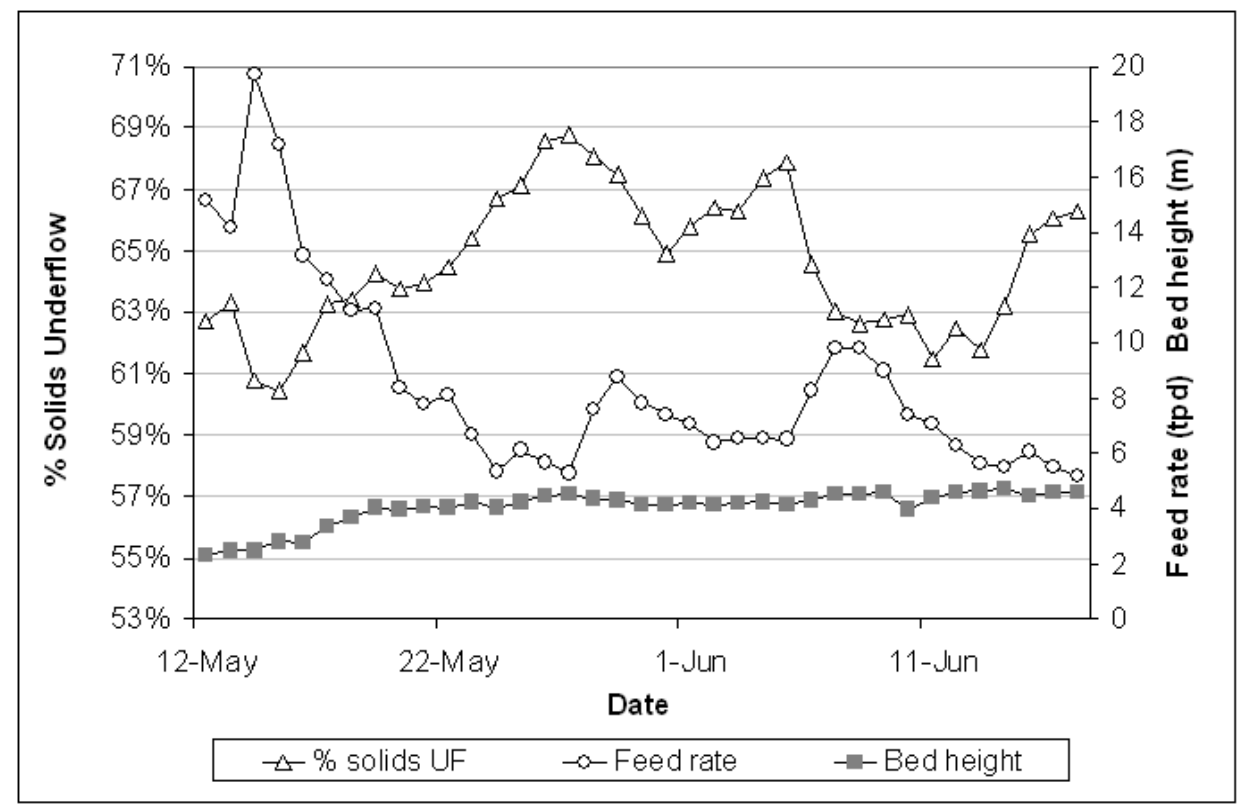

Figure 5 Average results from pilot plant campaign

The tests were highly influenced by changes in the feed mineralogy, thus in the phase I to IV campaigns the mineral processed were predominantly porfiritic latite, so it was possible to reach near $69 \%$ solids in underflow.

In the Phase V campaign the objective was to obtain $65-66 \%$ solids in the underflow, thus it would be required to increase the feed rate, even though due to changes in the mineral properties it wasn't possible to increase the feed rate, as shown in Figure 5 where the under flow \% solids decrease as well as the feed rate. 
Only in the last campaign was it possible to increase \% mass solids underflow because of the change in the mineralogy to porfiritic latite rocks again. The bed height was maintained near five metres in all the campaigns with over $65 \%$ mass solids objective requirements.

Continuously along the test period the three technology providers carried out rheological tests over unsheared and sheared samples, as a reference it was registered un-sheared yield stress in a range of 50-400 $\mathrm{Pa}$ a corresponding to $60-70 \%$ solids by mass.

The yield stress of the un-sheared underflow at solids density of $65-66 \%$ mass, shows high resistance to flow as it has a yield stress between $100-200 \mathrm{~Pa}$, which is dependant on the mineralogy, \% solids and particle size distribution. This is also largely due to the effect of the flocculent, and can be reduced by shearing the sample. Tests run in the pilot channel show that it is possible to reduce the initial yield stress by the shearing effect given by the tailing flowing through the channel.

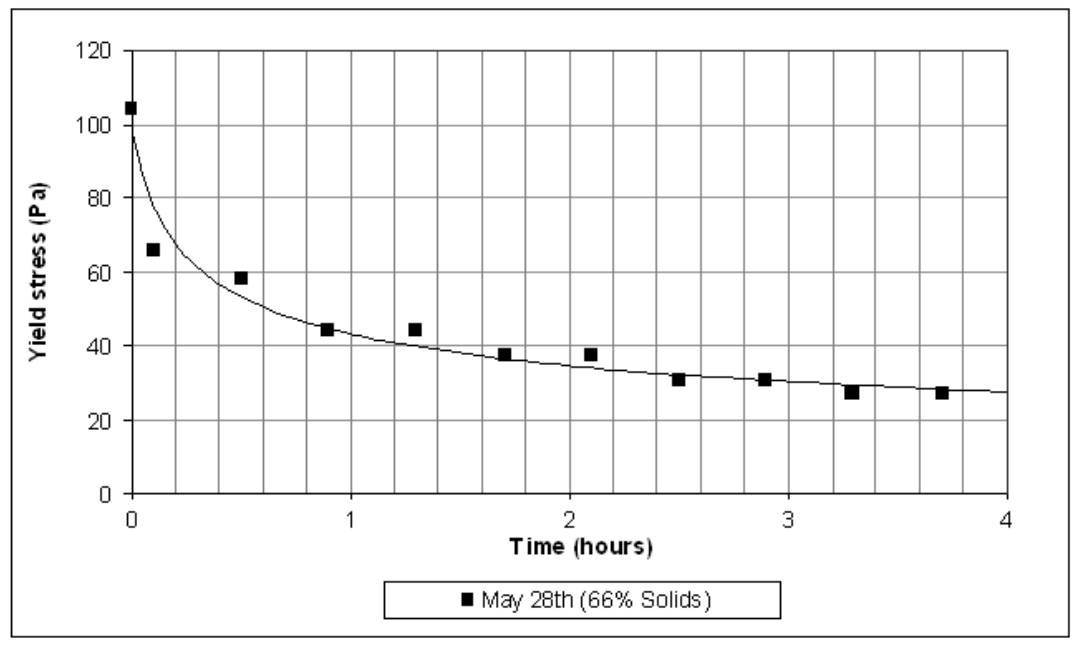

Figure 6 Yield stress reduction by the effect of the flowing tailings

Figure 6 shows that the discharge of the thickener has high yield stress, which can be reduced by the shearing, in the first hours (tailing flowing through the channel) the resistance is significantly reduced, however there is a limit in the yield stress reduction and it is be highly dependent on the rheological properties of the sample.

The gravity flow is also dependent on the channel slope, and tests were carried out at critical channel slopes to determine the level at which the yield stress must be reduced to let the tailings flow. Figure 7 shows that tailings with $66 \%$ solids and $2.5 \%$ of channel slope, require a yield stress reduction to at least $60 \mathrm{~Pa}$ for it to flow by gravity, and at slopes of $1.5 \%$ the yield stress must be less than $50 \mathrm{~Pa}$.

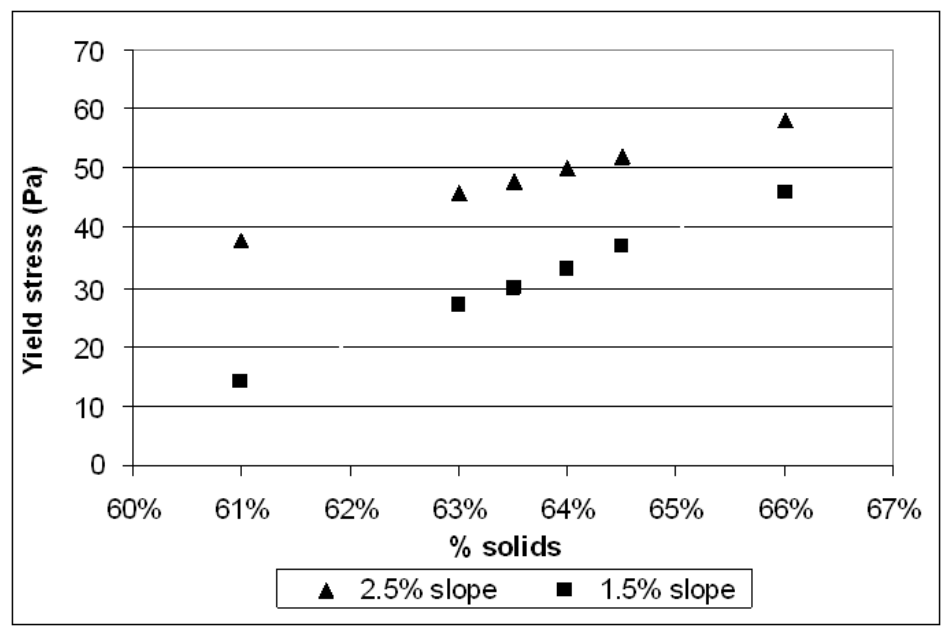

Figure 7 Minimum yield stress required to flow by gravity 


\section{Conclusions}

It is possible to produce highly densified underflow from the Cuajone tailing using high compression technologies.

According to the rheological characterisation of the Cuajone tailings, below $66 \%$ mass solids it can flow by gravity and the yield stress must be reduced to $60 \mathrm{~Pa}$. It means that an industrial scale shearing system must be installed in the discharge of the thickener to lower the yield stress.

It is possible to recover water at least at a rate of 315 litres/s from the Cuajone tailings. The rate would be higher depending on the feed solids density.

Table 2 Water recovery sceneries as function of feed \% solids

\begin{tabular}{l|lllll}
\hline $\begin{array}{l}\text { Feed } \\
\text { \% Solids }\end{array}$ & \multicolumn{5}{|c}{ Water recovery (Litres/s) } \\
Underflow \% Solids \\
\hline & $61 \%$ & $63 \%$ & $\mathbf{6 5 \%}$ & $67 \%$ & $69 \%$ \\
$48 \%$ & 477 & 500 & $\mathbf{5 4 9}$ & 595 & 639 \\
$50 \%$ & 363 & 416 & $\mathbf{4 6 5}$ & 511 & 555 \\
$52 \%$ & 286 & 338 & $\mathbf{3 8 7}$ & 434 & 477 \\
$\mathbf{5 4 \%}$ & $\mathbf{2 1 4}$ & $\mathbf{2 6 6}$ & $\mathbf{3 1 5}$ & $\mathbf{3 6 2}$ & $\mathbf{4 0 5}$ \\
$55 \%$ & 180 & 180 & $\mathbf{2 8 2}$ & 328 & 371 \\
\hline
\end{tabular}

\section{Acknowledgement}

The authors wish to thank Delkor, FLSmidth, Golder Associates and Outotec for their cooperation in the development of this important project for SCC.

\section{References}

Gladman, B.J., Usher, S.P. and Scales, P.J. (2006) Understanding the thickening process, Proceedings of the Ninth International Seminar on Paste and Thickened Tailings 2006, R.J. Jewell, S. Lawson, P. Newman (eds), Australian Centre for Geomechanics, Perth, Australia, pp. 5-12.

Sofra, F. (2006) Rheological assessment - a road map for plant designers and operators, Proceedings of the Ninth International Seminar on Paste and Thickened Tailings 2006, R.J. Jewell, S. Lawson, P. Newman (eds), Australian Centre for Geomechanics, Perth, Australia, pp. 13-24.

Usher, S.P. (2002) Suspension dewatering: characterization and optimization, PHD Thesis in Department of Chemical Engineering, The University of Melbourne, Australia, $330 \mathrm{p}$. 